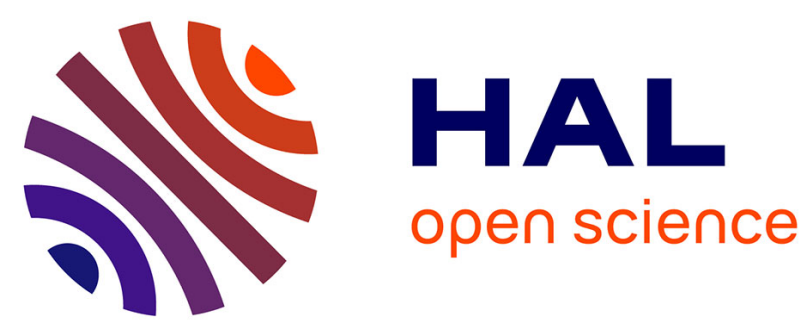

\title{
CMUT sensors based on circular membranes array for SHM applications
}

\author{
Pauline Butaud, Gilles Bourbon, Patrice Le Moal, Eric Joseph, Benoît Verdin, \\ Emmanuel Ramasso, Vincent Placet
}

\section{- To cite this version:}

Pauline Butaud, Gilles Bourbon, Patrice Le Moal, Eric Joseph, Benoît Verdin, et al.. CMUT sensors based on circular membranes array for SHM applications. Smart Structures + Nondestructive Evaluation, Mar 2019, Denver, United States. hal-02370490

\section{HAL Id: hal-02370490 https://hal.science/hal-02370490}

Submitted on 19 Nov 2019

HAL is a multi-disciplinary open access archive for the deposit and dissemination of scientific research documents, whether they are published or not. The documents may come from teaching and research institutions in France or abroad, or from public or private research centers.
L'archive ouverte pluridisciplinaire HAL, est destinée au dépôt et à la diffusion de documents scientifiques de niveau recherche, publiés ou non, émanant des établissements d'enseignement et de recherche français ou étrangers, des laboratoires publics ou privés. 


\title{
CMUT sensors based on circular membranes array for SHM applications
}

\author{
Butaud P., Bourbon G., Le Moal P., Joseph E., Verdin B., Ramasso E., and Placet V. \\ University of Bourgogne Franche-Comté - FEMTO-ST Department of Applied Mechanics, \\ Besançon, France
}

\begin{abstract}
A MEMS sensor dedicated to SHM applications is presented. The MEMS is made of a Capacitive Micromachined Ultrasonic Transducer (CMUT) chip composed of circular membranes array. The radius of the membranes vary between $50 \mu \mathrm{m}$ and $250 \mu \mathrm{m}$ and hence the associated resonance frequencies between $80 \mathrm{kHz}$ and $2 \mathrm{MHz}$. A wide frequency bandwidth is then available for acoustic measurements. A testing campaign is conducted in order to characterize the MEMS sensor's behavior when subjected to single-frequency and broadband excitation stimuli. The single-frequency excitations are produced with specific piezoelectric transducers from $300 \mathrm{kHz}$ to $800 \mathrm{kHz}$. The Fast Fourier Transform (FFT) of the measured signal from the CMUT is centered as expected on the excitation frequency. The broadband excitation is obtained with a pencil lead break. In this case, the FFT of the measured signal is centered on the resonance frequency of the membrane. These characterizations point out the DC bias voltage applied to the CMUT as a major parameter for controlling the sensitivity of the sensor. The CMUT sensor proves to be sufficiently sensitive to monitor these sources. This work highlights the relevant prospective capacities of the CMUT sensor to collect data in structural health monitoring applications. This sensor technology could be externally deployed, or even integrated into a composite structure, in order to monitor the structure by the CMUT detection, either by active ultrasound tests or by passive acoustic emission.
\end{abstract}

Keywords: MEMS, CMUT sensor, SHM, experimental characterization

\section{INTRODUCTION}

The development and the improvement of sensors to monitor and control infrastructures is a current challenge of our society. Indeed several recent accidents involving collapse of structures stimulate the development and the improvement of the Structural Health Monitoring in order to anticipate failures on mechanical structures and thus performing maintenance at the right time and place.

The refinement of the SHM involves the enhancement of the data processing but also the development of efficient sensors. The sensors must be able to be embedded and must not disturb the mechanical behavior of the structure. Several technologies are investigated, as piezolectric sensor, ${ }^{1}$ piezo-MEMS ${ }^{2}$ or optical fiber. ${ }^{3,4}$ We propose in this paper to investigate the MEMS technology (MUMPS), and more precisely the Capacitive Micromachined Ultrasonic Transducers (CMUT) technology. ${ }^{5,6}$ The proof of concept for SHM applications has been demonstrated during the last decade..$^{7-9}$ They have shown that, in spite of a low signal-to-noise ratio compared to the piezoelectric transducer, the CMUTs are able to detect, for example, acoustic emission events. In our work, the CMUTs of interest have been developed by Galisultanov et al. ${ }^{10}$ and the technology is presented in the next section. A numerical study to optimize the sensor design is presented. An experimental characterization is then proposed to highlight the potential of this CMUT sensor for SHM applications. Finally conclusions are drawn.

Send correspondence to

Le Moal P.: patrice.lemoal@femto-st.fr 


\section{SENSOR DESIGN}

A CMUT is an electrostatic transducer consisting mainly of a vibrating membrane acting as a sensor/receiver of acoustic waves like a microphone. The vibro-acoustic characteristics of a CMUT cell in terms of center frequency, bandwidth and vibration amplitude are determined by the geometric and mechanical properties of the membrane, the bias voltage applied to the membrane and the surrounding medium.

In this work, perforated circular membranes clamped at periphery are considered with radius varying from $50 \mu \mathrm{m}$ to $250 \mu \mathrm{m}$. This radius range, the thickness (around $1.3 \mu \mathrm{m}$ ) and the constitutive material (i.e. polysilicon) determine the frequencies range from $80 \mathrm{kHz}$ to $2 \mathrm{MHz}$.

Holes are designed in the membranes in order to control the effects of squeeze film damping and stiffening. Indeed, the air-filled cavity under the membrane acts as additional spring and damper causing resonance frequency shift and large decrease of the vibration amplitude respectively. Holes also lead to damping due to viscous and thermal losses allowing to enhance the sensor bandwidth. In this work, holes are $10 \mu \mathrm{m}$ diameter with $20 \mu \mathrm{m}$ pitch distance and distributed in a non-staggered configuration.

On the one hand, arrays of identical membranes allow the sensor sensitivity to be improved. Indeed, the global electric capacitance of the sensor is increased and as a consequence the electric current induced by the membranes vibrations. On the other hand, array of different membranes allow the bandwidth to be increased. The global bandwidth is supposed to be composed of the superposition of each membrane bandwidth centered on its own resonance frequency.

\subsection{Manufacturing process}

The sensors are manufactured using the standard fabrication process Multi-User MEMS Processes (MUMPS, run \#120). The top and sectional views of a typical membrane layout are proposed on Figure 1. The basis of the process is a silicon substrate with a nitride layer for isolation. The ground and feed electrodes are patterned in the initial polysilicon layer (known as Poly 0). Both silicon oxide sacrificial layers (known as Ox 1 and Ox 2) are then deposited and have to be released to form the electrostatic gap. At last, the perforated membranes are patterned in the second polysilicon layer (known as Poly 2).

Anchor posts are made at periphery to achieve clamping conditions. It can be noticed that the electric track of the ground electrode from the region under the membrane to the pad requires an opening in the annular clamping, thereby possibly altering the clamping conditions.

The dimensions of the chip are $5 \times 5 \mathrm{~mm}^{2}$ area and $0.6 \mathrm{~mm}$ height, with more than 60 membranes on it. Single CMUT cells and several arrays of CMUT membranes are designed on the chip. Single CMUT cells are mainly devoted to validation tests for the resonance frequency and the pull-in voltage. The radius of the membranes varies between $50 \mu \mathrm{m}$ and $250 \mu \mathrm{m}$, the thickness (Poly 2) and the electrostatic gap (Ox $1+\mathrm{Ox} 2$ ) are measured by profilometry respectively around $1.30 \mu \mathrm{m}$ and $2.40 \mu \mathrm{m}$.
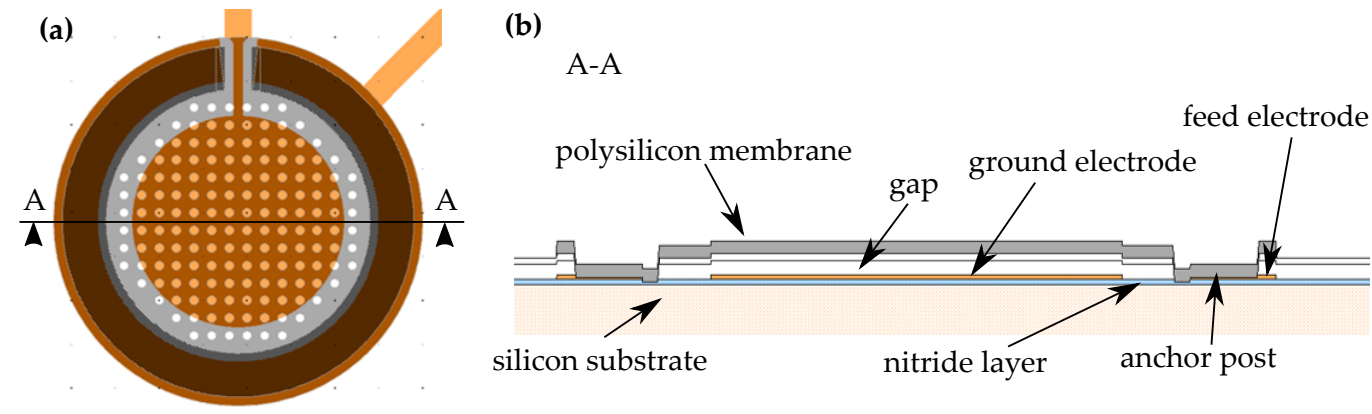

Figure 1. (a) Top and (b) sectional views of a typical membrane layout. 


\subsection{Numerical study}

The CMUT circular cells have to be designed in order to cover at least the $100 \mathrm{kHz} 1 \mathrm{MHz}$ frequency range according to the acoustic emissions in composite materials. Closed-form solutions of the vibrations of circular plates have been developed by Leissa ${ }^{11}$ determining the resonant frequency $f$ as

$$
f=\frac{\lambda^{2}}{2 \pi R^{2}} h \sqrt{\frac{E}{12 \rho\left(1-\nu^{2}\right)}},
$$

with $R$ and $h$ the radius and the thickness of the membrane respectively, $E, \nu$ and $\rho$ the Young modulus, the Poisson ratio and the density of the constitutive material of the membrane respectively, and $\lambda$ a parameter depending on the boundary conditions and the considered vibration mode (as defined by the number of nodal circles and nodal diameters). In this context, the first vibration mode is concerned with clamped boundary conditions at the periphery, i.e. no nodal circle (except the clamped periphery) and no nodal diameter. Therefore, the parameter $\lambda$ is around 10.2158 .

Knowing $h=1.30 \mu \mathrm{m}, E=160 \mathrm{GPa}, \nu=0.22$ and $\rho=2330 \mathrm{~kg} / \mathrm{m}^{3}$, a membrane radius range can be identified for the expected frequency range. The results based on this approach are reported in Table 1 as analytical ones, i.e. six different membrane radius 50, 75, 100, 150, 200 and $250 \mu \mathrm{m}$ with the corresponding first mode resonant frequencies.

The real geometry of the CMUT cells presented in Figure 1 is quite different from that of a circular membrane meeting the assumptions of the analytical approach. Four key differences can be raised: a non-uniform thickness of the membrane due to the Poly 0 ground electrode step, specific clamping conditions due to the sidewall link between the membrane and the anchor posts, holes perforating the membrane and lastly, the opening in the annular clamping allowing the electric track to pass through.

\begin{tabular}{lcccccc}
\hline Radius $[\mu \mathrm{m}]$ & 50 & 75 & 100 & 150 & 200 & 250 \\
\hline Analytical results $[\mathrm{kHz}]$ & 2073 & 921 & 518 & 230 & 130 & 83 \\
Numerical model $[\mathrm{kHz}]$ & 2074 & 924 & 516 & 229 & 128 & 84 \\
\hline
\end{tabular}

Table 1. Resonance frequency $f_{0}$ according to the radius of the membrane, estimated analytically and b numerical simulation.

Therefore, FEM modal analysis is undertaken based on the ANSYS finite element software. A solid model meshed by 20 node hexahedral SOLID186 elements is considered in order to point out the geometrical particularities. Figure 2(a) presents the complete meshing of the structure, Figure 2(b) shows a zoom on the opening in the annular clamping. Due to time-consuming 3D numerical simulations, this model requires a very slight worsening of the meshing size for radius higher than $75 \mu \mathrm{m}$. Practically, the size element is increased by $1 \mu \mathrm{m}$ $(100 \mu \mathrm{m} / 150 \mu \mathrm{m}: 1 \mu \mathrm{m}$ to $2 \mu \mathrm{m}, 200 \mu \mathrm{m}: 2 \mu \mathrm{m}$ to $3 \mu \mathrm{m}, 250 \mu \mathrm{m}: 3 \mu \mathrm{m}$ to $3.9 \mu \mathrm{m})$.
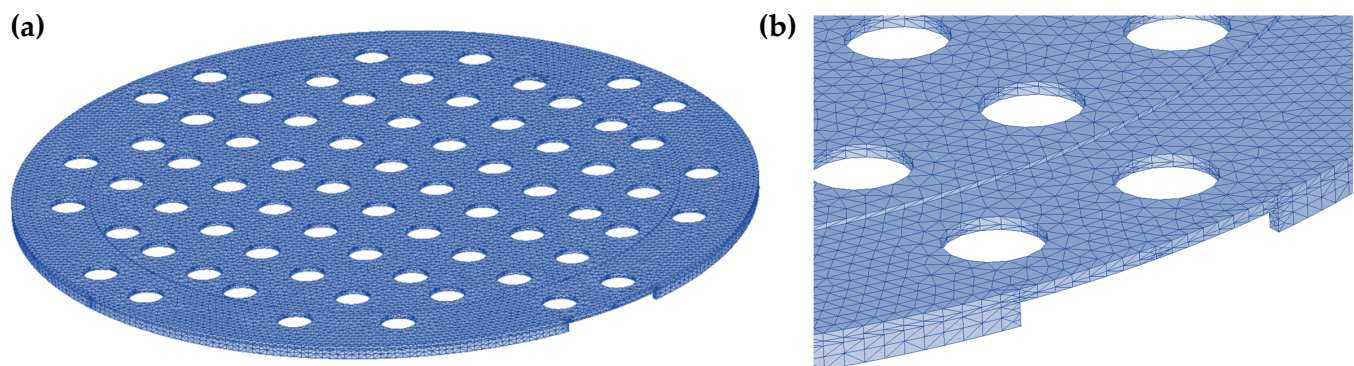

Figure 2. (a) Complete model of the membrane and (b) a zoom on the opening in the annular clamping.

As a conclusion, the numerical model taken into account all the geometric features lead to very slight variations of the first mode resonant frequency: lower than $0.51 \%$ for $50 \mu \mathrm{m}$ to $150 \mu \mathrm{m}$ radius, and $1.30 \%$ for $200 \mu \mathrm{m}$ to 
$250 \mu \mathrm{m}$ radius, comparing with the analytical results (see Table 1. Indeed the real geometries involve stiffening and softening effects counterbalancing one another.

Another key point for the membrane design is the identification of the pull-in voltage corresponding to the membrane collapse. This characteristic determines the operating range of the sensor since the higher the DC bias voltage, the higher the generated electric current is for a given capacitance variation. Table 2 reports the analytical values calculated for a perfectly clamped circular uniform membrane on the basis of the approach described by Nikoozadeh et al. ${ }^{12}$

\begin{tabular}{lcccccc}
\hline Radius $[\mu \mathrm{m}]$ & 50 & 75 & 100 & 150 & 200 & 250 \\
Pull-in voltage $[\mathrm{V}]$ & 466.6 & 207.3 & 116.5 & 51.6 & 28.6 & 18.3 \\
\hline
\end{tabular}

Table 2. Pull-in voltage according to the radius of the membranes.

In the next section the work is focusing on the $100 \mu \mathrm{m}$ radius membranes and the experimental characterizations are presented.

\section{EXPERIMENTAL CHARACTERIZATIONS}

\subsection{Materials and methods}

Figure 3 presents the experimental setups. Acoustic waves propagation through an aluminum beam is studied. The aluminum beam considered is $200 \mathrm{~mm}$ length, $30 \mathrm{~mm}$ width and $3 \mathrm{~mm}$ height. Two kinds of excitation are used to characterize the CMUT: a monofrequency excitation and a broadband excitation. In this paper, the results on an array of 9 membranes of $100 \mu \mathrm{m}$ radius are presented. The acoustic waves propagation is also observed with a classical Micro80-type sensor (Mistras Group Ltd.) used as a reference. Both sensors are attached on one end of the aluminum beam with a spring clamp to ensure a permanent contact, and coated with industrial coupling gel to ensure good transmission of the signal. The sensor signals are recorded with an oscilloscope (Picoscope 4824). The CMUT is powered by a Cooknell power supply SU3/C and an amplifier $\mathrm{CA} 7 / \mathrm{C}$. The DC bias voltage applied on the CMUT is adjusted between $0 \mathrm{~V}$ and $60 \mathrm{~V}$.
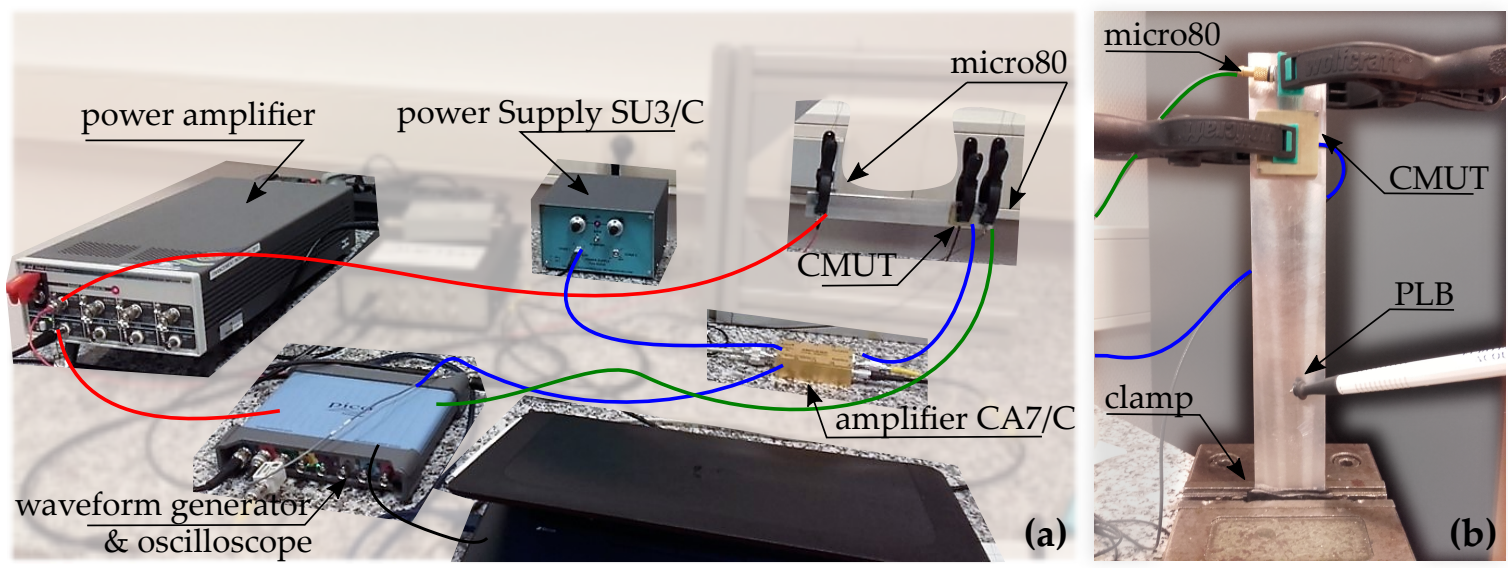

Figure 3. Experimental setups for (a) harmonic excitation and (b) broadband excitation.

Waveforms generation using an ultrasonic transducer Figure 3(a) shows the experimental setup used to obtain an harmonic excitation. In this case the beam is in free-free condition, hanging by wires. The transducer used as a transmitter is a Micro80-type sensor which has an operating frequency-range of $[200900 \mathrm{kHz}]$ and a resonance frequency of $325 \mathrm{kHz}$. Its dimensions are $9 \mathrm{~mm}$ diameter and $11 \mathrm{~mm}$ height. The input signal of the transducer is created using a waveform generator (Picoscope 4824, $5 \mathrm{MS} / \mathrm{s}$ ) and a power amplifier (Tabor Electronics 9100 A, with a fixed gain of 50). A 6-cycle sine wave windowed excitation is used at different 
frequencies $(300,530$ and $800 \mathrm{kHz})$. A typical excitation signal measured at the output of the waveform generator is shown in Figure 4. It has to be mentioned that the transducer and amplifier will have an impact on the input signal due to their characterizations.
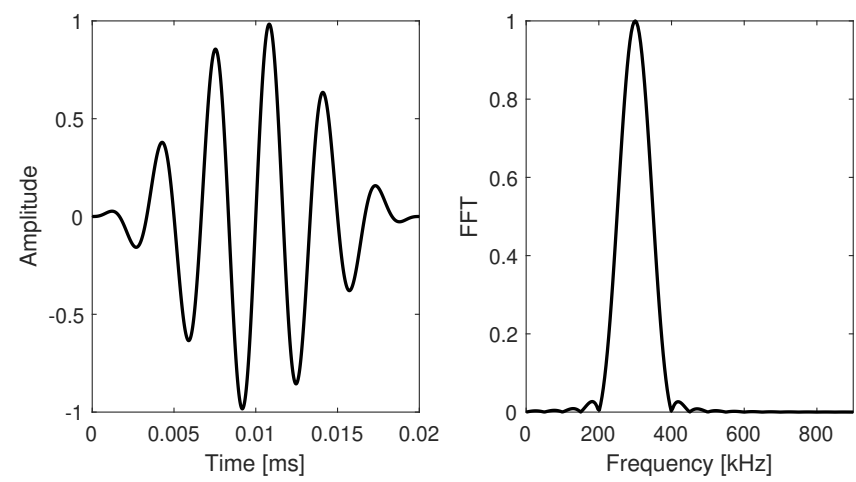

Figure 4. Excitation signal at $300 \mathrm{kHz}$ : a 6 -cycle sine wave windowed excitation, temporal signal and its FFT.

Waveforms generation using Pencil Lead Breaks The PLB is used to obtain a broadband excitation. The PLB is applied on the specimen as shown on Figure 3(b). In this configuration, the aluminum beam is clamped on one side. The $2 \mathrm{H}$ lead has a $0.5 \mathrm{~mm}$ diameter, and it is broken with a length of about $2 \mathrm{~mm}$.

\subsection{Results for harmonic excitation}

Figure 5(a) presents the FFT (Fast Fourier Transform) of the temporal signals measured at $300 \mathrm{kHz}$ and for a power $V_{D C}$ between 0 and $60 \mathrm{~V}$ with steps at $10 \mathrm{~V}$. Figure $5(\mathrm{~b})$ shows a linear relationship between the bias voltage and the CMUT response amplitude.
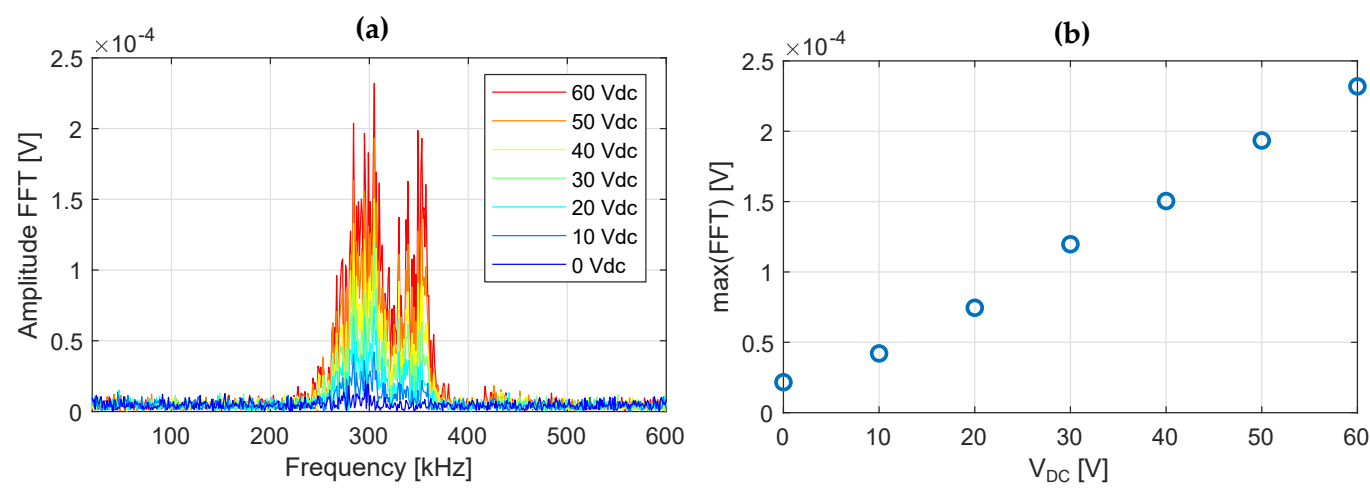

Figure 5. Influence of the $V_{D C}$ on the CMUT measured signal, (a) FFT of the temporal signal, (b) evolution of the maximum amplitude according to the $V_{D C}$.

Figure 6 presents the temporal signal, and Morlet Continuous Wavelet Transform (CWT), measured for an harmonic excitation at $300 \mathrm{kHz}, 500 \mathrm{kHz}$ and $800 \mathrm{kHz}$, on the $100 \mu \mathrm{m}$ radius membranes family powered at $60 V_{D C}$. On the temporal signals, it can be observed that according to the excitation frequency, the amplitude of the response is not the same. The maximum amplitude is obtained for $500 \mathrm{kHz}$ (Figure $6 \mathrm{~b}$ top) with $5 \mathrm{mV}$ peak, this is related to the resonance frequency of the R100 membrane $\left(f_{0}=450 \mathrm{kHz}\right)$.

On the CWT associated to each signal (Figure 6 bottom), it can be observed that the R100 frequency signature is centered on the excitation frequency. Therefore the R100 family is sensitive on a wide band of frequencies. 
(a)
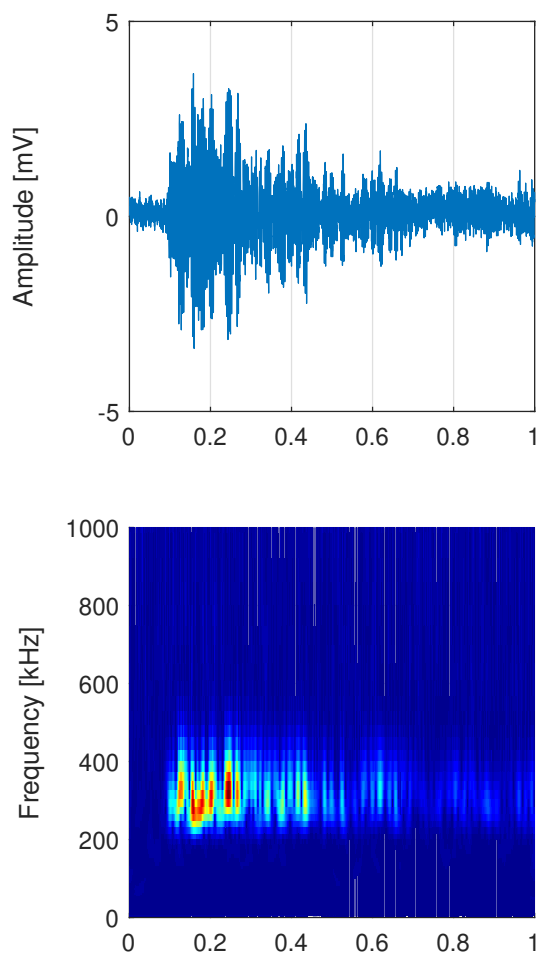

(b)
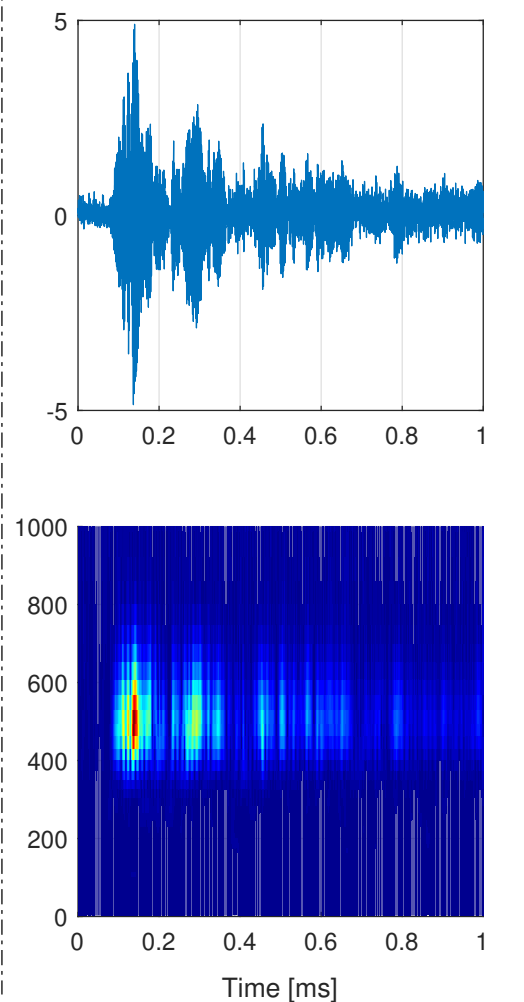

(c)
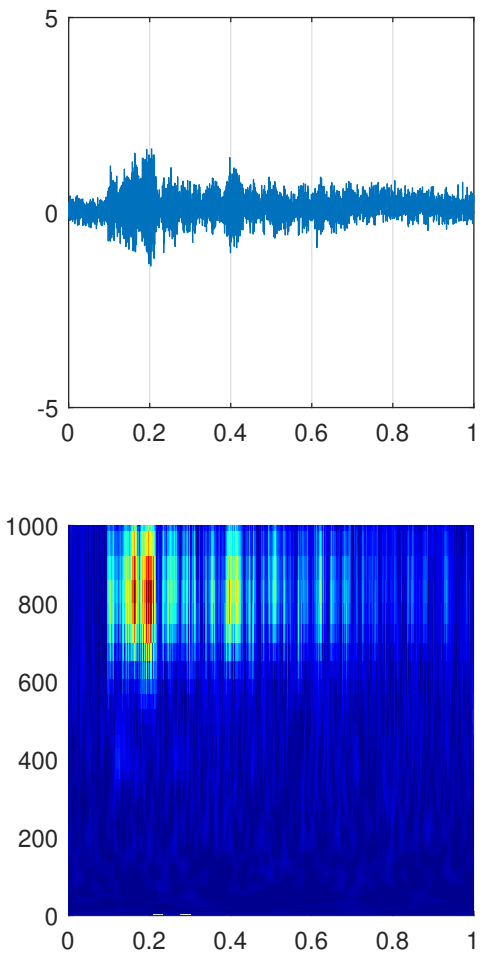

Figure 6. Temporal signal and Morlet CWT measured for an harmonic excitation at (a) $300 \mathrm{kHz}$, (b) $500 \mathrm{kHz}$ and (c) $800 \mathrm{kHz}$, with $V_{D C}=60 \mathrm{~V}$.

\subsection{Results for a broadband excitation (PLB)}

In this section we use an artificial source commonly used in acoustic emission. Figure 7 shows the temporal signal measured with the CMUT R100 family and presents the associated CWT and the FFT of this signal. It can be observed a higher magnitude in the CWT centered around $450 \mathrm{kHz}$ as on the FFT of the signal. This frequency corresponds to the resonance frequency of the sensor. Thus, the acoustic emission signal measured by the CMUT is not wide-band as expected but corresponds to the transfer function of the sensor. This kind of excitation permits to highlight the footprint of the sensor. The same conclusions can be observed with the Micro80 piezoelectric sensor. 
(a)

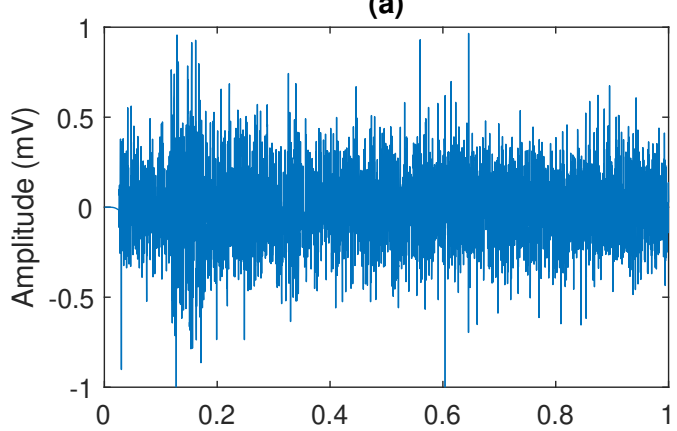

(b)

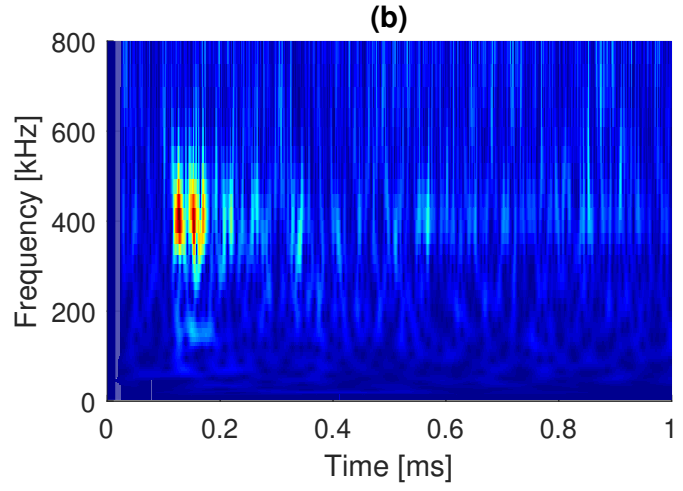

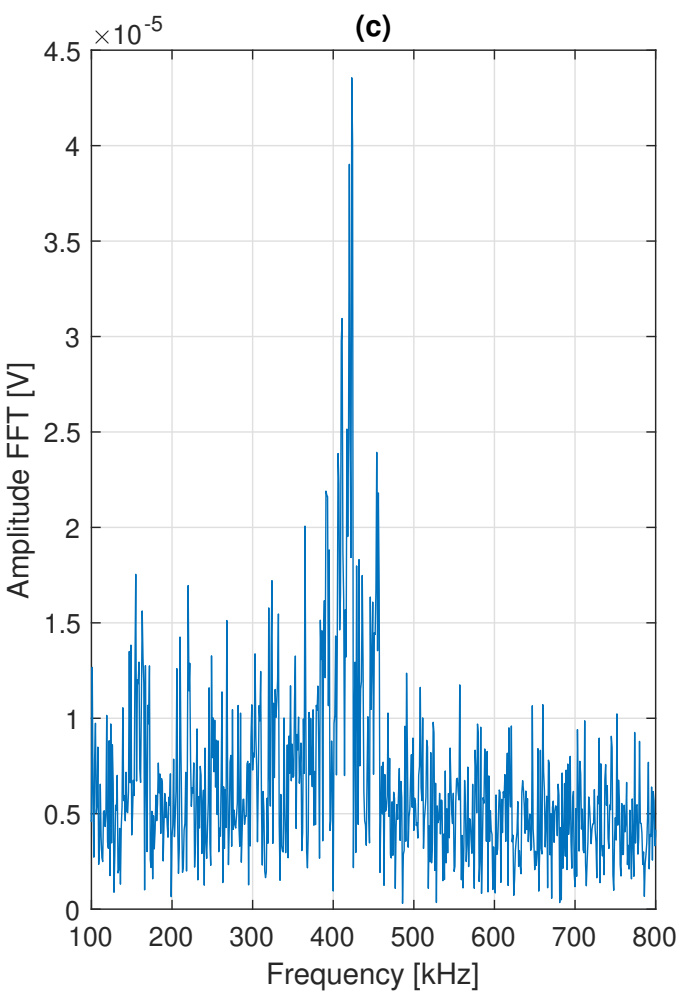

Figure 7. CMUT response to a Pencil lead break, (a) temporal signal, (b) Morlet CWT and (c) FFT.

\section{CONCLUSIONS}

A CMUT sensor is developed and characterized. The design procedure to obtain a sensitive sensor on a wide band of frequencies is described through an analytical approach and expanded with a numerical model. The experimental characterization is done with two kinds of excitation (harmonic and broadband excitation) and permits to capture the electro-mechanical behavior of the sensor. Finally this work highlights the relevant prospective capacities of the CMUT sensor to collect data in structural health monitoring applications. For that the next step will be to improve the signal noise ratio. An idea could be to increase the number of membranes, indeed at this time a family of nine membranes has been tested but a family of 50 membranes could be a possibility. Besides, the design of the chip could be adjusted to be externally deployed, or even integrated into a composite structure, in order to monitor the structure by the CMUT detection, either by active ultrasound tests (similar to harmonic excitation) or by passive acoustic emission (similar to PLB excitation).

\section{Acknowledgment}

This work has been supported by the EIPHI Graduate School (contract "ANR-17-EURE-0002"). This work was partly supported by the french RENATECH network and its FEMTO-ST technological facility.

\section{REFERENCES}

[1] Chandarana, N., Sanchez, D., Soutis, C., and Gresil, M., "Early damage detection in composites during fabrication and mechanical testing," Materials 10(7), 685 (2017).

[2] Kabir, M., Kazari, H., and Ozevin, D., "Piezoelectric mems acoustic emission sensors," Sensors and Actuators A: Physical 279, 53 - 64 (2018).

[3] García, I., Zubia, J., Durana, G., Aldabaldetreku, G., Illarramendi, M., and Villatoro, J., "Optical fiber sensors for aircraft structural health monitoring," Sensors 15(7), 15494-15519 (2015). 
[4] Bremer, K., Weigand, F., Zheng, Y., Alwis, L., Helbig, R., and Roth, B., "Structural health monitoring using textile reinforcement structures with integrated optical fiber sensors," Sensors 17(2), 345 (2017).

[5] Oppenheim, I. J., Jain, A., and Greve, D. W., "Electrical characterization of coupled and uncoupled mems ultrasonic transducers," IEEE Transactions on Ultrasonics, Ferroelectrics, and Frequency Control 50(3), 297-304 (2003).

[6] Oppenheim, I. J., Jain, A., and Greve, D. W., "Mems ultrasonic transducers for the testing of solids," IEEE transactions on ultrasonics, ferroelectrics, and frequency control 50(3), 305-311 (2003).

[7] Ozevin, D., Greve, D., Oppenheim, I., and Pessiki, S., "Resonant capacitive mems acoustic emission transducers," Smart materials and structures 15(6), 1863 (2006).

[8] Hutchins, D., Billson, D., Bradley, R., and Ho, K., "Structural health monitoring using polymer-based capacitive micromachined ultrasonic transducers (cmuts)," Ultrasonics 51(8), 870-877 (2011).

[9] Saboonchi, H., Ozevin, D., and Kabir, M., "Mems sensor fusion: Acoustic emission and strain," Sensors and Actuators A: Physical 247, 566-578 (2016).

[10] Galisultanov, A., Le Moal, P., Bourbon, G., and Walter, V., "Squeeze film damping and stiffening in circular cmut with air-filled cavity: Influence of the lateral venting boundary conditions and the bias voltage," Sensors and Actuators A: Physical 266, 15-23 (2017).

[11] Leissa, A. W., "Nasa sp-160," Vibration of plates , 59-60 (1969).

[12] Nikoozadeh, A., Bayram, B., Yaralioglu, G. G., and Khuri-Yakub, B. T., "Analytical calculation of collapse voltage of cmut membrane [capacitive micromachined ultrasonic transducers]," in [Ultrasonics Symposium, 2004 IEEE], 1, 256-259, IEEE (2004). 